\title{
Kerentanan Kejadian Penyakit Berbasis Lingkungan Pada Masyarakat Terdampak Bencana Di Daerah Pesisir Kabupaten Donggala
}

\author{
Pitriani* $^{* 1}$, Sitti Radhiah ${ }^{2}$, Kiki Sanjaya ${ }^{1}$ \\ ${ }^{13}$ Department of Enviromental Health, Faculty of Publich Health, Tadulako University \\ ${ }^{2}$ Department of Reproduction Health, Faculty of Publich Health, Tadulako University
}

Author's Email Correspondence (*): pitriarifinkl07@gmail.com

Phone : +6282194358197

\begin{abstract}
ABSTRAK
ISPA dan diare yang merupakan penyakit berbasis lingkungan selalu masuk dalam 10 besar penyakit tertinggi di hampir seluruh puskesmas di Indonesia1. Hendrik L. Bloom mengemukakan lingkungan sebagai faktor utama determinan kesehatan masyarakat, kerentanan masyarakat terhadap penyakit ISPA dan diare berkaitan erat dengan sanitasi dasar dan kondisi fisik rumah. Berdasarkan studi pendahuluan diketahui kejadian penyakit berbasis lingkungan meningkat tajam di Kelurahan Boneoge pasca bencana. Penelitian ini bersifat deskriptif dengan pendekatan SIG yang bertujuan melihat sebaran kejadian penyakit berbasis lingkungan dikaitkan dengan ketersediaan fasilitas sanitasi dasar dan kondisi fisik rumah. Populasi penelitian adalah semua keluarga yang bermukim di Boneoge. Penarikan sampel secara cluster random sampling dimana perwakilan sampel diambil dari 3 RW dengan jumlah keseluruhan $90 \mathrm{KK}$. Penentuan titik koordinat rumah responden menggunakan GPS, analisa data spasial dengan aplikasi Arc view GIS 3.3. Pendataan ketersediaan fasilitas sanitasi dasar dan kondisi fisik rumah responden menggunakan kuesioner terstandar dan disajikan dalam bentuk tabel distribusi frekuensi. Dari hasil pengumpulan data diketahui faktor lingkungan fisik rumah berupa kepadatan hunian $(57.8 \%)$ dan jenis dinding rumah $(65.5 \%)$ responden masuk dalam kategori kerentanan tinggi terhadap kejadian ISPA sedangkan aspek luas ventilasi (65.5\%) masih memenuhi syarat kesehatan, demikian juga aspek perilaku merokok dalam rumah tidak berpotensi menyebabkan kerentanan ISPA pada masyarakat setempat. Faktor akses terhadap sanitasi dasar menunjukkan kebutuhan air bersih masyarakat telah terpenuhi, sebaliknya rendahnya kepemilikan jamban (60\% KK tidak memiliki jamban) merupakan kerentanan tinggi terhadap kejadian diare.
\end{abstract}

Kata Kunci: Penyakit Berbasis Lingkungan, SIG, ISPA, Diare, Sanitasi Dasar 


\begin{abstract}
ARI and diarrhea which is environmental disease is a ten highest disease in almost all health centers in Indonesia. Hendrik L. Bloom suggests the environment as a major determinant of public health, vulnerability to ARI and diarrhea are closely related to basic sanitation and the physical condition of the house. Based on a preliminary study of the incidence of environmental diseases known to increases sharply in the Boneoge urban village after the disaster. Cluster random sampling applied in which a representative sample is taken from 3 hamlet with a total of 90 households. Determination of the respondent's house coordinates using a GPS, spatial data analysis with Arc view GIS 3.3. Documenting the availability of basic sanitation facilities and physical condition using a standardized questionnaire and presented in the form of a frequency distribution table. Tata data collection described physical environmental factors is a density residential (57.8\%) and the type of houses walls (65.5\%) of respondents in the category of high vulnerability to ARI while the ventilation (65.5\%) still meets the health requirements, as well as smoking behavior at the houses that are not potentially cause vulnerability of ARI in the community. Access to basic sanitation based water availability are met, otherwise the low latrine ownership (60\% of households do not have latrine) is a high vulnerability to diarrhea.
\end{abstract}

Keywords: Environmental Disease, GIS, ARI, diarrhea, Sanitation

\title{
PENDAHULUAN
}

ISPA dan diare yang merupakan penyakit berbasis lingkungan selalu masuk dalam 10 besar penyakit tertinggi di hampir seluruh puskesmas di Indonesia (1)(2) . Data Riset Kesehatan Dasar tahun 2018 menunjunkkan angka kesakitan akibat penyakit berbasis lingkungan berdasarkan diagnose tenaga kesehatan dan gejala, seperti ISPA mencapai 9.3\% dan diare pada balita $12.3 \%$ (3). UNICEF juga merilis laporan yang menyimpulkan bahwa di Indonesia ISPA dan diare merupakan penyakit berbasis lingkungan yang berkontribusi tinggi terhadap morbiditas dan mortalitas khususnya pada balita (4). Dari data-data ini tercermin besarnya kontribusi penyakit berbasis lingkungan terhadap derajat kesehatan masyarakat.

Hendrik L. Bloom (1974) mengemukakan derajat kesehatan masyarakat dipengaruhi oleh empat faktor, dimana lingkungan sebagai faktor utama (5)(6). Faktor lingkungan khususnya aspek sanitasi dasar dan kondisi fisik rumah berkaitan erat dengan kerentanan 
masyarakat terhadap penyakit berbasis lingkungan (7). Sejalan dengan teori H.L Bloom, WHO (2019) melaporkan bahwa kondisi sanitasi dasar dan personal hygene yang buruk masuk dalam The Leading Global Risk for Burden Risk Disease (2). Sanitasi dasar diartikan sebagai kesehatan lingkungan minimal yang harus dimiliki setiap keluarga untuk memenuhi kebutuhan sehari-hari. Ruang lingkup sanitasi dasar mencakup penyediaan air bersih, ketersediaan jamban keluarga, sarana pembuangan sampah dan sarana pembuangan air limbah (8)(9).

Kelurahan Boneoge berada di daerah pesisir kabupaten Donggala tepatnya di kecamatan Banawa, Kelurahan ini terkena dampak cukup parah akibat bencana gempa bumi dan tsunami tanggal 28 Oktober 2018. Berdasarkan studi pendahuluan diketahui Kelurahan Boneoge dihuni $892 \mathrm{KK}$, dengan jumlah penduduk laki-laki sebanyak 1.745 jiwa dan perempuan 1.663 jiwa dan data laporan tahunan Puskesmas Pembantu Boneoge diketahui pasca gempa kejadian ISPA dan diare masuk dalam 10 penyakit tertinggi. Data-data kejadian penyakit di wilayah tersebut masih diolah secara manual dengan penyajian terbatas dalam bentuk tabel dan grafik, sehingga pemetaan yang berbasis Sistem Infomasi Geografis (SIG) belum dilakukan sama sekali.

Pemetaan kerentanan masyarakat terhadap penyakit berbasis lingkungan perlu dilakukan sehingga diperoleh informasi akurat terkait potensi kejadian penyakit dalam suatu wilayah. Analisis spasial menggunakan SIG sangat mendukung untuk pengambilan keputusan dalam penanggulangan penyakit berbasis lingkungan. Prinsip dasar dari konsep ini adalah pemanfaatan SIG untuk mengkonversi data populasi, data penyakit, data lingkungan, fasilitas kesehatan, dll menjadi bentuk visual seperti peta dan grafik guna memudahkan interpretasi data penyakit serta mendukung pengambilan keputusan terkait program penanggulangan penyakit berbasis lingkungan.

Pada penelitian ini akan dilakukan observasi dan pengumpulan data lapangan sehingga diperoleh gambaran kaitan antara aspek sanitasi dasar dan kondisi fisik rumah dengan kejadian penyakit berbasis lingkungan di wilayah tersebut. Hasil penelitian ini, dapat menjadi data awal untuk melakukan pemetaan kerentanan masyarakat desa Boneoge terhadap kejadian penyakit ISPA dan diare, dan dapat menjadi acuan untuk memperkirakan kerentanan desa-desa pesisir lainnya apabila karakteristik masyarakatnya tidak jauh berbeda. Pemetaan kejadian penyakit berbasis lingkungan ini diharapkan dapat membantu intansi terkait 
misalnya puskesmas, dinas kesehatan kabupaten Donggala dan akademisi agar program penyuluhan kesehatan atau program intervensi lainnya lebih tepat sasaran.

\section{METODE}

Penelitian ini bersifat deskriptif dengan pendekatan sistem informasi geografis (SIG). Populasi pada penelitian ini semua keluarga yang masih bermukim di Desa Boneoge berdasarkan data Monografi Keluarahan Boneoge Tahun 2019, yaitu 892 KK. Penarikan sampel secara cluster random sampling, dimana pembagian cluster berdasarkan RW pada kelurahan Boneoge. Menggunakan rumus slovin di peroleh jumlah sampel keseluruhan 90 $\mathrm{KK}(\mathrm{d}$ = tingkat kepercayaan/ketepatan yang diinginkan 0,1$)$. Kemudian sampel dibagi secara proportiol berdasarkan jumlah KK dalam setiap RW, diperoleh rincian sampel per RW yaitu $\mathrm{RW} 1=27 \mathrm{KK}, \mathrm{RW} 2=27 \mathrm{KK}$ dan RW $3=36 \mathrm{KK}$.

Penentuan titik koordinat rumah penderita menggunakan GPS (Global Position System) secara manual, analisa data spasial dengan aplikasi Arc view GIS 3.3. Serta pendataan ketersediaan fasilitas sanitasi dasar dan kondisi fisik rumah masyarakat menggunakan kuesioner terstandar dan disajikan dalam bentuk tabel distribusi frekuensi.

\section{HASIL}

\section{Gambaran Umum Responden}

Berdasarkan data pada tabel 1, dapat dilihat bahwa sebagian besar responden memiliki anggota keluarga lebih dari 4 yaitu sebanyak 64 responden (71.1\%), dimana idealnya rumah dihuni oleh 1 keluarga yang terdiri dari 4 orang saja. 
Tabel 1.

Distirbusi Frekuensi Responden Pemetaan Kejadian Penyakit Berbasis Lingkungan di Desa Boneoge Kecamatan Banawa Tahun 2020

\begin{tabular}{lll}
\multicolumn{1}{c}{$\begin{array}{c}\text { Karakteristik Umum } \\
\text { Responden }\end{array}$} & (n) & \% \\
\hline Umur (Tahun) & 6 & 6.67 \\
$17-25$ & 22 & 24.4 \\
$26-35$ & 21 & 4 \\
$36-45$ & 22 & 23.3 \\
$46-55$ & 13 & 3 \\
$56-65$ & 6 & 24.4 \\
$>65$ & & 4 \\
& & 14.4 \\
& & 5 \\
& & 6.67 \\
\hline Jenis Kelamin & 29 & 32.2 \\
Laki-laki & 61 & 0 \\
Perempuan & & 67.8 \\
& & 0 \\
\hline Pendidikan Terakhir & & \\
\hline Tamat SD & 53 & 58.9 \\
\hline Tamat SMP/Sederajat & 19 & 21.1 \\
\hline Tamat SMA/Sederajat & 18 & 20.0 \\
\hline Jumlah Anggota Keluarga & & \\
\hline$\leq 4$ orang & 26 & 28.9 \\
\hline$>$ 4 orang & 64 & 71.1 \\
\hline Sumber : Data Primer, 2020 & & \\
\hline
\end{tabular}

Sebaran lokasi tempat tinggal responden secara rinci dipetakan pada gambar 1.

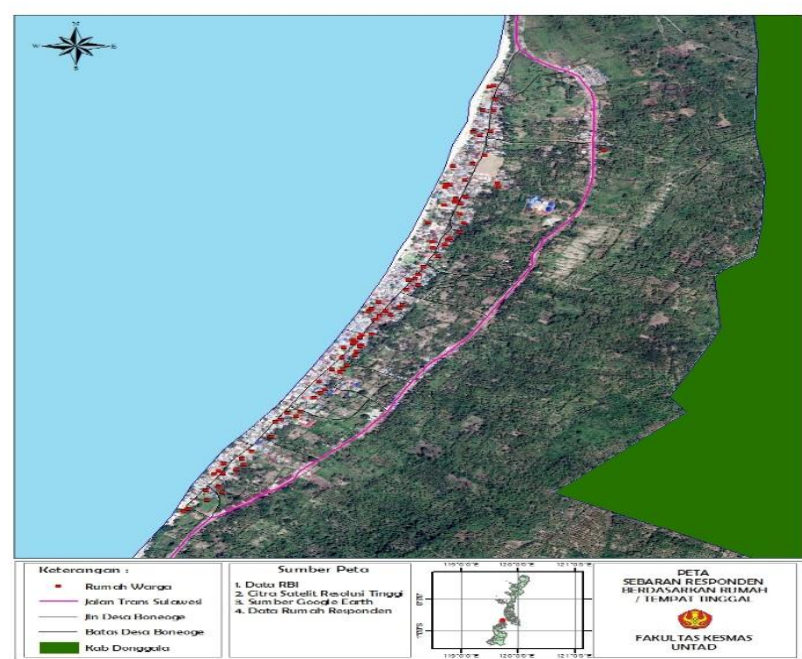


Gambar 1.

Sebaran Tempat Tinggal Responden Kelurahan Boneoge

Kecamatan Banawa Kabupaten Donggala

Tabel 2.

Kerentanan Kejadian ISPA dan Diare di Desa Boneoge Kec. Banawa Tahun 2020

\begin{tabular}{|c|c|c|c|}
\hline Faktor Lingkungan Fisik Rumah & $\mathbf{n}$ & $\%$ & Keterangan \\
\hline \multicolumn{4}{|l|}{ Kepadatan Hunian (Min $9 \mathrm{~m}^{2} /$ orang) } \\
\hline Memenuhi syarat & 38 & 42.2 & Kerentanan Rendah \\
\hline Tidak Memenuhi Syarat & 52 & 57.8 & Kerentanan Tinggi \\
\hline \multicolumn{4}{|l|}{ Luas Ventilasi (Min 20\% luas lantai) } \\
\hline Memenuhi syarat & 59 & 65.5 & Kerentanan Rendah \\
\hline Tidak Memenuhi Syarat & 31 & 34.5 & Kerentanan Tinggi \\
\hline \multicolumn{4}{|l|}{ Jenis dinding } \\
\hline Memenuhi syarat & 38 & 42.2 & Kerentanan Rendah \\
\hline Tidak Memenuhi Syarat & 52 & 57.8 & Kerentanan Tinggi \\
\hline \multicolumn{4}{|l|}{ Perilaku Merokok dalam rumah } \\
\hline Tidak & 72 & 80 & Kerentanan Rendah \\
\hline Ya & 18 & 20 & Kerentanan Tinggi \\
\hline \multicolumn{4}{|l|}{ Ketersediaan Air Bersih (Min } \\
\hline $\begin{array}{l}\text { 60L/orang/hari) } \\
\text { Tidak Tersedia }\end{array}$ & $\begin{array}{c}1 \\
89\end{array}$ & $\begin{array}{l}11.1 \\
88.9\end{array}$ & $\begin{array}{l}\text { Kerentanan Rendah } \\
\text { Kerentanan Tinggi }\end{array}$ \\
\hline \multicolumn{4}{|l|}{ Tersedia } \\
\hline \multicolumn{4}{|l|}{ Ketersediaan Jamban Keluarga } \\
\hline Tidak Tersedia & 36 & 40.0 & Kerentanan Rendah \\
\hline Tersedia & 54 & 60.0 & Kerentanan Tinggi \\
\hline
\end{tabular}

Sumber : Data Primer, 2020

\section{PEMBAHASAN}

\section{Kerentanan ISPA ditinjau Dari Aspek Lingkungan Fisik Rumah}

Hasil observasi lapangan dan wawancara terhadap 90 KK diperoleh data kondisi fisik rumah (Tabel 2), terlihat bahwa dari aspek kepadatan hunian sebagian besar rumah responden tidak memenuhi syarat yaitu 52 KK (57.8\%). Demikian juga jenis dinding, lebih banyak rumah menggunakan dinding non-permanen (batu bata/batako tanpa di plester, papan, anyaman bambu). Kondisi ini berbanding terbalik dengan luas ventilasi, 59 KK (65.5\%) memenuhi syarat ideal $>20 \%$ total luas lantai. Demikian juga aspek paparan asap rokok dalam ruang, sebagian besar responden menyatakan anggota keluarga tidak merokok didalam rumah, yaitu 72 responden $(80 \%)$.

Kondisi sanitasi rumah yang buruk berkaitan dengan berbagai gangguan kesehatan secara luas, termasuk di dalamnya gangguan sistem pernapasan akut (10). Mengatasi 
permasalahan sanitasi perumahan dapat menjadi jalan bagi praktisi kesehatan untuk menangani faktor risiko sosial yang penting dari kesehatan. Sektor kesehatan telah lama terlibat dalam isu-isu penyehatan perumahan, bahkan sejak tahun 1900an sektor kesehatan telah menargetkan aspek rendahnya sanitasi, kepadatan hunian dan kurangnya ventilasi dalam upaya menurunkan risiko kejadian penyakit infeksi (11)(12).

Permasalahan kesehatan yang berkaitan dengan kondisi perumahan merupakan beban kesehatan yang penting, terutama jika dikaitkan dengan buruknya kondisi udara dalam ruang dan rendahnya akses terhadap air bersih (1)(13). Berdasarkan hasil rekapitulasi data pada tabel 2, menunjukkan bahwa sebagian besar masyarakat Desa Boneoge memiliki kerentanan tinggi terhadap kejadian ISPA berdasarkan aspek kepadatan hunian dan jenis dinding rumah, sedangkan untuk aspek luas ventilasi dan paparan asap rokok dalam ruang masih dikategorikan kerentanan rendah.

Kepadatan hunian dapat diartikan suatu kondisi dimana jumlah penghuni melebihi kapasitas ruang hunian yang tersedia. Menentukan kepadatan hunian dapat dilakukan dengan membandingkan total luas lantai dengan jumlah penghuni (14) . Keputusan Menteri Pemukiman dan Prasarana Wilayah Nomor 403 Tahun 2002, menyebutkan bahwa syarat ideal luas lantai dengan jumlah penghuni $>9 \mathrm{~m}^{2} /$ orang. Dalam artian, rumah sederhana (tipe 36) hanya dapat dihuni maksimal 4 orang saja.

Hasil temuan dilapangan pada penelitian ini ditemukan bahwa 57.8\% KK dalam penelitian ini masuk dalam kategori kerentanan tinggi terhadap kejadian ISPA jika dilihat dari aspek kepadatan huniannya. Tingginya kepadatan hunian masyarakat dapat dikaitkan dengan jumlah anggota rumah tangga yang dimiliki setiap KK. Pada tabel 1 terdapat $71.1 \%$ KK memiliki anggota rumah tangga $>4$ orang. Temuan dilapangan juga dikonfirmasi bahwa terdapat rumah tangga dengan jumlah anggota keluarga hingga 11 orang. Banyaknya jumlah anggota keluarga tentunya harus dibarengi dengan kapasitas ruang yang besar. Disamping aspek luas hunian, masyarakat desa Boneoge juga tidak begitu memperhatikan aspek kamarisasi dan penataan ruang. Dari hasil pengamatan dilapangan, peneliti melihat bahwa hanya sedikit rumah responden yang memiliki kamar tidur terpisah dengan anak-anak. Ratarata rumah hanya memiliki 1 kamar tidur. Kondisi ini tentunya tidak sehat dan mempermudah penularan penyakit infeksi antara anggota keluarga. Kondisi rumah yang sempit dan umumnya tanpa kamarisasi tentunya berkaitan erat dengan kondisi ekonomi masyarakat. 
Data monografi Kelurahan Boneoge Kecamatan Banawa Kabupaten Donggala Tahun 2020 menunjukkan bahwa sebagian besar masyarakat di Kelurahan Boneoge berprofesi sebagai nelayan tangkap ( $73 \%$ dari total masyarakat usia kerja) yang mengantungkan perekonomian dari hasil laut. Hal ini menyebabkan sebagian besar masyarakat memiliki kondisi rumah tidak memenuhi standar fisik rumah sehat.

Aspek fisik rumah yang juga sering dikaitkan dengan kejadian ISPA adalah jenis dinding dan lantai rumah. Idealnya dinding rumah harus kedap air serta bebas dari bahan berbahaya (15).Temuan dilapangan menujukkan bahwa $57.8 \%$ rumah responden masih menggunakan dinding semi permanen dengan lantai kasar (semen kasar). Kondisi dinding seperti ini berpotensi meningkatkan kadar partikulat (debu halus dalam rumah), peluruhan dari bahan dasar batu bata/batako atau papan dapat beterbangan diudara. Keberadaan partikulat dalam rumah tentunya akan meningkatkan durasi pemaparan, hal ini dikarenakan sebagaian besar orang menghabiskan banyak waktunya di dalam rumah saat sedang tidak bekerja. Demikian juga masyarakat desa Boneoge, mereka banyak berdiam di rumah saat sedang tidak melaut (bekerja).

Jenis dinding yang permanen seperti tembok dapat dibersihkan dari debu dan dapat mencegah debu masuk kedalam rumah. Namun jenis dinding rumah seperti papan, kayu, batako umumnya seringkali menghasilkan serat debu di permukaannya dan sangat mudah menyatu dengan debu yang beterbangan didalam rumah sehingga dapat menjadi faktor resiko terjadinya ISPA (3)(16).

Peraturan menteri kesehatan R.I. No 1077/MENKES/PER/V/2011 tentang Pedoman Penyehatan Udara dalam Ruang Rumah juga telah mengatur bahwa persyaratan kualitas udara dalam ruang rumah dari aspek fisik, terdiri dari parameter: partikulat (Particulate Matter yaitu PM2,5 dan PM10), suhu udara, pencahayaan, kelembaban, serta pengaturan dan pertukaran udara (laju ventilasi). Sehingga jelas bahwa penggunaan dinding rumah tidak permanen akan meningkatkan kadar Particulate Matter yaitu PM2,5 dan PM10 dalam ruang. Hal ini tentunya akan meningkatkan potensi paparan pada setiap anggota rumah tangga saat sedang beraktivitas maupun beristirahat di dalam rumah.

Mengacu pada WHO yang diadaptasi dalam Permenkes RI Nomor 1077 Tahun 2011, bahwa salah satu syarat fisik rumah sehat yaitu luas ventilasi rumah idealnya 5-20\% dari total luas lantai, dengan rincian 5\% untuk rumah didataran tinggi, 10\% untuk rumah di dataran rendah dan $20 \%$ untuk rumah di daerah pesisir dengang tekanan udara rendah (15). Hasil 
temuan dilapangan (tabel 2) menunjukkan bahwa 65.5\% rumah responden telah memenuhi syarat minimal 20\% ventilasi dari total luas lantai. Disamping itu masyarakat pada umumnya masih menggunakan ventilasi alamiah melalui jendela, pintu, lubang angin dan lubanglubang pada dinding. Penggunaan ventilasi buatan seperti menggunakan kipas angin dan mesin penghisap udara (exhaust van) hanya ditemukan pada beberapa rumah saja.

Ventilasi dapat diartikan sebagai proses penyediaan udara atau pengerahan udara dari ruangan baik secara alami maupun mekanis. Perlu diperhatikan bahwa sistem pembuatan ventilasi harus dijaga agar udara tidak terperangkap, tetapi harus mengalir. Sehingga konsep pembuatan ventilasi harus berupa ventilasi silang, artinya dalam ruangan harus ada jalan masuk dan kelur udara dengan arah berlawanan (17)(12). Pada observasi lapangan, diketahui meskipun rumah-rumah masyarakat cenderung sempit namun jendela-jendela dibuat cukup lebar dan sering dibuka, bahkan pintu rumah juga lebih sering dibuka sepanjang hari saat penghuni berada dirumah. Hal ini memungkinkan mengingat kondisi masyarakat pedesaan yang masih cukup humanis dibandingkan dengan masyarakat kota. Kebiasaan membuka pintu dan jendela rumah dapat menjadi alternatif agar sirkulasi udara dalam rumah berlangsung dengan baik. Disamping itu membuka pintu dan jendela juga membantu sinar matahari masuk ke dalam ruangan, sehingga perkembangbiakan mikroorganisme seperti jamur dan lainnya dapat ditekan.

Asap rokok merupakan salah satu sumber indoor air pollution, sehingga perilaku merokok dalam rumah diduga sebagai salah satu determinan dari kejadian ISPA khususnya pada balita yang umumnya lebih rentan terhadap penyakit infeksi. Hal ini dapat dipahami, sebab secara fisiologis perkembangan organ tubuh termasuk organ-organ pernafasan mereka masih belum sempurna (18)(19). Hasil tabulasi data menunjukkan bahwa hanya $20 \%$ dari responden menyatakan ada anggota keluarganya yang biasa merokok di dalam rumah. Hal ini dikarenakan, sebagian besar kepala rumah tangga dan anggota rumah tangga (usia kerja) menghabiskan waktu dilaut sejak sore hingga dini hari, mereka lebih banyak melaut dan kebanyakan dari mereka merokok saat sedang melaut.

Asap rokok yang dilepaskan ke udara mengandung berbagai bahan kimia yang dapat tercampur dengan partikulat lainnya diudara, dan dapat tetap berada dalam ruangan hingga waktu yang cukup lama. merilis, asap rokok dapat bertahan di udara 2-3 jam bahkan saat ventilasi rumah atau jendela dibuka. Rokok memiliki efektivitas sangat tinggi dalam menyebarkan bahan kimia beracun jika diisap di dalam rumah. Berbagai zat beracun yang 
keluar saat rokok dibakar tidak hanya mencemari ruangan tempat seseorang merokok, tetapi akan menyebar ke seluruh ruangan di dalam rumah. Asap rokok juga dapat mengendap pada pakaian, rambut dan tangan perokok serta benda-benda lain disekitarnya termasuk di lantai. Hal ini akan semakin membahayan balita mengingat mereka sering bermain di lantai dan menyentuh benda-benda disekitarnya dan memasukkan benda-benda kecil atau tangan ke dalam mulutnya.

Tidak berlebihan jika dikatakan kondisi perumahan yang baik dapat menyelamatkan nyawa, mengurangi risiko penyakit khususnya penyakit menular, meningkatkan kualitas hidup penghuninya dan tentunya berkontribusi pada pencapaian sejumlah tujuan SDG's diantaranya tujuan ke 3 (Good Health and Well Being) dan ke 11 (Sustaenable Cities and Communities).

\section{Kerentanan Diare ditinjau dari Aspek Akses Fasilitas Sanitasi Dasar}

Sejak zaman John Snow (1813-1858 M) kita ketahui bahwa kontaminasi air dapat memicu outbreak (wabah) akibat waterborne disease, salah satunya diare (20). Kualitas air yang buruk, telah lama dikaitkan dengan kejadian diare khususnya pada balita. Hasil studi menunjukkan (tabel 2), bahwa hampir semua responden menyatakan telah memiliki akses air bersih yang layak yaitu $88.9 \%$. Dimana hampir semua rumah telah memiliki sumur terlindung dan beberapa memiliki sumur bor sebagai sumber air bersih, adapun rumah yang belum memiliki sumur sendiri biasanya mengambil air dari sumur milik tetangga. Secara kuantitas mereka telah memenuhi kebutuhan air bersih, meskipun tidak ada patokan pasti kebutuhan air bersih harian setiap orang. Kebutuhan rata-rata perkapita penduduk Indonesia belum diketahui tetapi untuk keperluan perencanaan instalasi pengolahan air bersih komunitas, perkiraan kebutuhan air bersih berkisar 125-150 liter/orang/hari. Tingkat penggunaan air rumah tangga juga akan berbeda setiap negara dan berbeda pada kelas ekonomi tertentu. survey yang dilakukan kementerian PUPR tahun 2016 menyebutkan kebutuhan pokok minimal air bersih orang Indonesia per hari ada 70 liter/orang/hari (20). Dari temuan lapangan juga diketahui meskipun akses terhadap air bersih sudah cukup memadai namun kesadaran masyarakat terkait open defecation (Buang Air Besar Sembarangan) masih rendah. Hal ini tergambar dari masih banyaknya rumah yang tidak memiliki jamban keluarga. Pada tabel 2, terdapat $60 \%$ KK belum memiliki jamban. Mereka umumnya masih buang air besar di tepi pantai, dan sebagian menyatakan buang air besar dengan menumpang pada tetangga. 
Dapat dikatakan dari aspek ketersediaan air bersih, masyarakat Boneoge dikategorikan tidak rentan terhadap kejadian diare, sebaliknya jika dilihat dari aspek ketersediaan jamban maka sebagian besar masyarakat rentan terhadap kejadian diare. Bahkan masyarakat yang telah memiliki jamban sekalipun tetap berisiko tinggi terpapar E-coli dari tinja yang bertebaran di pantai sekitar tempat tinggal mereka. Kontaminasi tinja juga dapat memicu penyakit enterik lain, seperti kolera, disentri, typus dan sebagainya.

Rendahnya kesadaran masyarakat terkait perilaku BABS dapat dikaitkan dengan rendahnya tingkat pendidikan, mayoritas masyarakat Boneoge hanya tamat Sekolah Dasar, minimnya fasilitas pendidikan dan status ekonomi menjadi salah satu pemicu tingginya angka putus sekolah (7). Namun saat ini, pemerintah kelurahan telah menyediakan tambahan fasilitas pendidikan hingga tingkat SMP. Upaya ini telah mampu meningkatkan level pengetahuan penduduk khususnya generasi muda, tergambar dari data monografi kelurahan tahun 2020 menjelaskan bahwa Kelurahan Boneoge saat ini, mayoritas penduduk telah menyelesaikan pendidikan hingga ke tingkat SMP.

Perubahan ini juga diharapkan akan berimbas pada perilaku generasi muda setempat dalam menyikapi kebiasaan BABS yang turun temurun. Selain rendahnya pengetahuan sebagai faktor predisposisi, minimnya sarana prasarana (ketersediaan jamban keluarga) merupakan enabling factors tingginya perilaku BABS pada masyarakat., menyatakan ketersediaan sarana prasarana merupakan salah salah satu faktor utama pembentukan perilaku hidup sehat, termasuk perubahan perilaku BABS. Disamping itu peran tenaga kesehatan dan apparat desa/tokoh masyarakat dapat menjadi reinforcing factors dalam perubahan perilaku tersebut (5)(6).

\section{KESIMPULAN DAN SARAN}

Faktor lingkungan fisik rumah berupa kepadatan hunian dan jenis dinding rumah masyarakat di desa Boneoge, masuk dalam kategori kerentanan tinggi terhadap kejadian ISPA sedangkan aspek luas ventilasi masih memenuhi syarat kesehatan, demikian juga aspek perilaku merokok dalam rumah yang tidak berpotensi menyebabkan kerentanan ISPA pada masyarakat setempat. Faktor akses terhadap sanitasi dasar menunjukkan bahwa kebutuhan akan air bersih masyarakat telah terpenuhi, sebaliknya rendahnya kepemilikan jamban merupakan kerentanan tinggi terhadap kejadian diare. 


\section{DAFTAR PUSTAKA}

1. Prasetyo R, Siagian TH. Determinan Penyakit Berbasis Lingkungan Pada Anak Balita di Indonesia (Determinants Of Environmentally Based Diseases Among Children Under Five In Indonesia). J Kependud Indones. 2017;12(2):93-104.

2. Amiruddin, R., Arsin, A., Abdullah, Z. Modul Epidemiologi Dasar. Makassar: Universitas Hasanuddin, Fakultas Kesehatan Masyarakat Universitas Hasanuddin.; 2011.

3. Kementerian Kesehatan RI. Hasil Utama Riset Kesehatan Dasar. 2018;

4. UNICEF Indonesia. Ringkasan Kajian: Air Bersih, Sanitasi dan Kebersihan. 2012;

5. Achmadi U. Penyakit Berbasis Lingkungan. 1 st Ed. Jakarta: PT Raja Grafindo Persada; 2011.

6. Latifatul A. N. Hubungan Lingkungan Fisik Rumah dengan Kejadian Penyakit ISPA Pada Balita di desa Guyung Kecamatan Gerih Kabupaten Ngawi. Hub Lingkung Fis Rumah dengan Kejadian Penyakit ISPA Pada Balita di desa Guyung Kec Gerih Kabupaten Ngawi. 2019;116.

7. Marianta D, Chahaya I, Marsaulina I. the Relation Between Physical Quality Houses With Ari. 2015;

8. Koshal RK. Water pollution and human health. Water Air Soil Pollut. 1976;5(3):289-97.

9. Gan WQ, Sanderson WT, Browning SR, Mannino DM. Different types of housing and respiratory health outcomes. Prev Med Reports [Internet]. 2017;7:124-9. Available from: http://dx.doi.org/10.1016/j.pmedr.2017.05.018

10. Sunaryo. Analisis Spasial untuk Penyakit Berbasis Lingkungan. Semin Nas Upaya Pengendali Penyakit Berbas Wil. 2015;

11. Setiyono A. Faktor Risiko Kejadian Diare pada Masyarakat Kota Tasikmalaya. J Kesehat Komunitas Indones. 2019;15(2):49-59.

12. Krieger J, Higgins DL. Housing and health: Time again for public health action. Am $\mathbf{J}$ Public Health. 2002;92(5):758-68.

13. Brownson RC. Epidemiology in Public Health Practice: By A. Haveman-Nies, S. C. Jansen, J. A. M. van Oers, and P. van 't Veer. Am J Epidemiol. 2011;174(7):871-2.

14. Cardoso MRA, Cousens SN, De Góes Siqueira LF, Alves FM, D’Angelo LA V. Crowding: Risk factor or protective factor for lower respiratory disease in young children? BMC Public Health. 2004;4:1-8.

15. WHO. Annual Report : Diarrhoel Disease. 2019;

16. Muhajjar M, Rahardjo M, Dewanti N. Analisis Spasial Hubungan Kualitas Lingkungan Dengan Kejadian Diare Pada Balita Di Kecamatan Genuk Kota Semarang. J Kesehat Masy. 2016;4(3):807-16.

17. WHO and Climate \& Clean Air Coalition. Air Pollution, Climate dan Health. 2018;

18. Melvani RP, Zulkifli H, Faizal M. Analisis Faktor Yang Berhubungan Dengan Kejadian Diare Balita Di Kelurahan Karyajaya Kota Palembang. JUMANTIK (Jurnal Ilm Penelit Kesehatan). 2019;4(1):57.

19. Daud A. Dasar Kesehatan Lingkungan. 1st ed. Jakarta: Hasanuddin University Press; 2013.

20. PUPR PKP. Pemakaian Air Rumah Tangga Perkotaan. 2018; 